\title{
KAJIAN STRUKTUR KOMUNITAS EPIFAUNA TANAH DI KAWASAN HUTAN KONSERVASI GUNUNG SIBELA HALMAHERA SELATAN MALUKU UTARA
}

\author{
Abdu Mas’ud \\ Sundari \\ Jurusan PMIPA FKIP Universitas Khairun Ternate \\ E-mail: abdu_unk@yahoo.co.id
}

\begin{abstract}
This research to know: (1) Biodiversity land epifauna; (2) Relationship of environment factor physical-chemical with land epifauna biodiversity in conservation at area Forest Mount of Sibela. This method is Descriptif research with Pitfall trap Technique to collect land epifauna. The result of this research were : 1) Land epifauna at this research counted 74 species of epifauna which consist of 4 class, 18 ordo, 36 family and 63 genus; 2) Biodiversity of land epifauna at conservation forest shall be as follows: a) diversity index equal to 1,46475 category, b) eveness index equal to 0,35089 category of balanced, c) dominate index equal to 0,06280 category of to lower, d) important value of highest at species of Formica sanguine equal to 11,9817 ; 3) There are relationship is significant between of physical-chemical environment factor with diversity index. Found of this research can be exploited for the development of study of ecology concept and practical contribution about procedure research of simple desain of technique making of trap of land epifauna in the form of Pitfall trap at research focus of animal ecology (land arthropod) and also Entomological in Khairun of Ternate University.
\end{abstract}

Kata Kunci: biodiversitas, epifauna tanah, faktor lingkungan, konservasi Gunung Sibela

Salah satu cagar alam yang terdapat di Maluku Utara adalah Cagar Alam Gunung Sibela yang terletak di Pulau Bacan Kabupaten Halmahera Selatan, Provinsi Maluku Utara. Kawasan Cagar Alam Gunung Sibela memiliki luas 23.024 hektar. Gunung Sibela merupakan salah satu gunung yang tertinggi di Provinsi Maluku Utara dengan ketinggian 2.118 meter di atas permukaan laut. Potensi kawasan cagar alam Gunung Sibela antara lain adalah: (1) memiliki keanekaragaman jenis fauna seperti: monyet (Macaca nigra), burung Nuri Ternate (Lorius galurus), Bayan ((Eclectus roratus), burung Raja (Cicinnurus regius), Kasturi merah (Eos bornea), Kakatua putih (Cacatua alba), dan Perkicit violet (Eos squamata). (2) keanekaragaman jenis flora misalnya: Matoa (Pometia pinnata), Gufasa (Vitex cofassus), Samama (Anthocephalus macrophilus), Anggrek Alam serta Cengkeh alam yang sudah berumur ratusan tahun (cengkeh Avo).

Epifauna tanah adalah salah satu kelompok fauna yang hidup di tanah, 
baik yang hidup di permukaan tanah maupun yang terdapat di dalam tanah (Suin,1997). Salah satu epifauna tanah adalah kelompok Arthropoda. Arthropoda tanah memiliki peran secara umum sebagai dekomposer bahan organik tanah yang berfungsi dalam menyediakan komponen tanah. Faktor lingkungan yang dominan dapat mempengaruhi kehidupan fauna tanah. Apabila perubahan disebabkan oleh faktor lingkungan tersebut tidak menguntungkan bagi fauna tanah, maka respon yang akan diberikan oleh fauna tanah adalah penyesuaian diri terhadap perubahan tersebut. Jika penyesuaian diri tersebut berhasil, maka fauna tanah akan bertahan hidup, namun jika tidak mampu menyesuaikan diri maka fauna tanah akan memberikan respon bermacammacam terhadap perubahan faktor lingkungan tersebut. Penelitian ini dilakukan untuk mengkaji keanekaragaman epifauna tanah khususnya pada struktur komunitas yang terdapat di kawasan cagar alam gunung Sibela.

\section{METODE}

Sampel penelitian ini adalah seluruh epifauna tanah yang tertangkap pada titik-titik yang ditetapkan pada area sampling dikawasan hutan gunung Sibela. Pengambilan sampel epifauna tanah dengan menggunakan pithfall trap yaitu suatu perangkap yang dapat digunakan untuk mengukur aktifitas dan densitas fauna tanah. Pithfall trap ini sangat bermanfaat untuk mengetahui ritme aktivitas artropoda dan sebaran artropoda pada satu tipe vegetasi (Southwood, 1966). Pengambilan dan pengumpulan epifauna tanah ini mengikuti prosedur Uetz and Unzicker, (1976), dengan jarak tiap perangkap (titik tangkap) yaitu $5 \mathrm{~m}$. Data yang diperoleh dari hasil penelitian ini meliputi biodiversitas epifauna yang terdiri dari: Indeks keanekaragaman, Indeks kemerataan, Indeks kelimpahan, Indeks dominansi dan Nilai penting, dianalisis secara deskriptif. Analisis Regresi digunakan juga untuk melihat hubungan antara faktor lingkungan (fisik kimia) tanah yaitu suhu, $\mathrm{pH}$, kelembaban, dan persepsi masyarakat tentang fungsi ekologi hutan dengan biodiversitas (indeks Keanekaragaman) epifauna tanah di kawasan hutan gunung Sibela. Analisis Regresi ganda digunakan dalam penelitian ini, dengan rumus sebagai berikut:

F reg $=\frac{R^{2}(N-m-1}{M\left(1-R^{2}\right)}$

Hasil analisa data dilanjutkan dengan analisis sumbangan efektif (SE) setiap prediktor, dengan rumus sebagai berikut: SE \% X1 = SR\%X1 x R² (Hadi, 1982)

\section{HASIL}

\section{Biodiversitas Epifauna Tanah}

Berdasarkan hasil identifikasi jenis-jenis epifauna tanah yang ditemukan di hutan konservasi pada kawasan hutan gunung Sibela didapatkan sebanyak 74 spesies epifauna tanah yang terdiri dari 4 kelas, 18 ordo, 37 famili dan 63 genus. Data hasil identifikasi epifauna tanah seperti pada Tabel 1. Data seluruh indeks keanekaragaman epifauna tanah di kawasan hutan gunung Sibela disajikan pada Tabel 2. Data seluruh indeks kemerataan (evenes) epifauna tanah di kawasan hutan gunung Sibela disajikan pada Tabel 3. Data seluruh indeks kemelimpahan 
(Dominansi Simpson) epifauna tanah di kawasan hutan gunung Sibela tercantum pada Tabel 4.

Tabel 1: Hasil Identifikasi Epifauna Tanah yang Ditemukan pada Kawasan Hutan Gunung Sibela

\begin{tabular}{|c|c|c|c|c|}
\hline Kelas & Ordo & Famili & Genus & Spesies \\
\hline \multirow[t]{2}{*}{ Crustaceae } & Isopoda & Miliped & Polydesmus & Polydesmus complanatus \\
\hline & & Stenacellidae & Stenaselus & Stenaselus javaniscus \\
\hline \multirow[t]{10}{*}{ Arachnida } & Arachneae & Aglenidae & Tegenaria & Tegenaria deduellica \\
\hline & & & & Tegenaria agrestis \\
\hline & Amblypygi & Charontidae & Stygophynus & Stygophrynus dammermani \\
\hline & & & & Stygophynus sp 1 \\
\hline & & & & Stygophynus sp 2 \\
\hline & & & & Stygophynus sp 3 \\
\hline & Acari & Tetranichydae & Tetranichus & Tetranichus sp \\
\hline & & & Acariens & Acariens predateur \\
\hline & Opilianes & Epedanedae & Opiliones & Opiliones. $s p$ \\
\hline & Scorpionida & Thelyplonidae & Thelyplonus & Thelyplonus caudatus \\
\hline \multirow[t]{8}{*}{ Myriapoda } & Diplopoda & Hyleoglomeridae & Hyleoglomeris & Hyleoglomeris albicalis \\
\hline & & Diplopodiae & Diplopoda & Diplopoda sp1 \\
\hline & & & & Diplopoda sp2 \\
\hline & & & Jullus & Jullus. terrestris \\
\hline & & Chambalopsidae & Hipocambala & Hipocambala sp \\
\hline & Spirobolida & Spirobolidae & Chicobolus & Chicobolus spinigerus \\
\hline & Chilopoda & Scolopendridae & Scolopedro & Scolopedra subspinipes \\
\hline & & & & Scalopedra cingulata \\
\hline \multirow[t]{13}{*}{ Insecta } & Coleoptera & Scarabidae & Dinacoma & Dinacoma marginalis \\
\hline & & & Melolontha & Melolontha maculata \\
\hline & & & Aphodius & Aphodius granarius \\
\hline & & Scolytidae & Trypodendron & Trypodendron signatum \\
\hline & & & Hylurgops & Hylurgops palliatus \\
\hline & & Staphylinidae & Oxyporus & Oxyporus rufus \\
\hline & & & Xantholinus & Xantholinus sp \\
\hline & & & Stenus & Stanus $s p$ \\
\hline & & & Lardithon & Lardithon lunulatus \\
\hline & & Tenebrionidae & Bolithopagus & Bolitophagus reticulatus \\
\hline & & Crysomelidae & Donacia & Donacia aquatica \\
\hline & & Rhizophagidae & Rhizophagos & Rhizophagos cribratus \\
\hline & & Carabidae & Carabida & Adachanta Melanura \\
\hline
\end{tabular}




\begin{tabular}{|c|c|c|c|}
\hline & & \multirow{2}{*}{$\begin{array}{l}\text { Deporaus } \\
\text { Amara }\end{array}$} & \multirow{2}{*}{$\begin{array}{l}\text { Deporaus betulae } \\
\text { Amara sp }\end{array}$} \\
\hline & & & \\
\hline & Histeridae & Platycerus & Platycerus carambides \\
\hline \multirow[t]{3}{*}{ Blataria } & Blatelidae & Delophius & Dalopius margaritus \\
\hline & & Blatella & Blatella sp \\
\hline & & Opistoplatia & Opistoplatia orientalis \\
\hline \multirow[t]{8}{*}{ Orthoptera } & Acrididae & Scistocerca & Schistocerca damnifica \\
\hline & & Chortippus & Chorthippus brunnes \\
\hline & & Pholidoptera & Pholidoptera spcinerea \\
\hline & & Panthomorpha & Panthomorpha sp \\
\hline & & Gryllus & Gryillus bimaculatus \\
\hline & & Omacestus & Omacestus viridulans \\
\hline & Cholevidae & Choleva & Choleva spinipennis \\
\hline & Diastremidae & Diastremma & Diastremma sp \\
\hline \multirow[t]{17}{*}{ Hymenoptera } & Formicidae & Formica & Formica sanguena \\
\hline & & & Formica lemani \\
\hline & & & Formica subsericea \\
\hline & & & Hymen formica \\
\hline & & & Formica sp \\
\hline & & & Oecophylla smaradigna \\
\hline & & Damon & Damon diadema \\
\hline & & Pogonomyrmex & Pogonomyrmex badius \\
\hline & & Lasius & Lasius niger \\
\hline & & & Larius sp \\
\hline & & Myrmica & Myrmica rubra \\
\hline & & Componatus & Componatus pensilvaniaris \\
\hline & Trigonalidae & Lycogaster & Lycogster pulata \\
\hline & & Taeniogonalos & Taeniogonalos gundlachii \\
\hline & Vespidae & Evodynerus & Evodynerus sp \\
\hline & Stylopidae & Polistes & Polistes fuscatus \\
\hline & Branchionidae & Speciosus & Speciosus sp \\
\hline \multirow[t]{2}{*}{ Isoptera } & Rhinotermitidae & Coptotermes & Coptotermes formosanus \\
\hline & & Reticulitermis & Reticulitermis flavipes \\
\hline \multirow{4}{*}{$\begin{array}{l}\text { Collemboliform } \\
\text { es }\end{array}$} & Poduridae & Podura & Podura aquatica \\
\hline & & & \\
\hline & Entomobryidae & Collembola & Collembola sp 1 \\
\hline & & & Collembola sp 2 \\
\hline Dermatera & Arexenidae & Xeniaria & Xeniaria jacobsoni \\
\hline
\end{tabular}




$\begin{array}{llll}\text { Diptera } & \text { Bibionidae } & \text { Bibio } & \text { Bibio } s p \\ & \text { Drosophilidae } & \text { Drosophilla } & \text { Drosophilla } s p\end{array}$

Hemiptera Nitidulidae Limbata Limbata tibialis

Carcophilus Carcophilus hemipterus

Tabel 2: Indeks Keanekaragaman Epifauna Tanah di Kawasan Hutan Gunung Sibela

\begin{tabular}{|c|c|c|c|c|}
\hline \multirow{2}{*}{ Lokasi } & \multicolumn{3}{|c|}{ Indeks Keanekaragaman } & \multirow{2}{*}{ Rata-rata } \\
\cline { 2 - 4 } & Sasion I & Sasion II & Stasion III & \\
\hline Hutan Konservasi & 1,1792 & 1,5421 & 1,3532 & 1,4648 \\
\hline
\end{tabular}

Tabel 3 Indeks Kemerataan Epifauna Tanah di Kawasan Hutan Gunung Sibela

\begin{tabular}{|c|c|}
\hline Lokasi & Rata-Rata \\
\hline Hutan Konservasi & 0,35089 \\
\hline
\end{tabular}

Tabel 4 Indeks Kemelimpahan Epifauna Tanah di Kawasan Hutan Gunung Sibela

\begin{tabular}{|c|c|}
\hline Lokasi & Rata-Rata \\
\hline Hutan Konservasi & 0,06280 \\
\hline
\end{tabular}

Pada hutan konservasi memiliki INP spesies epifauna tanah (dibatasi pada 5 spesies tertinggi dan 5 spesies terendah), maka INP spesies epifauna tanah tertinggi 20.9735, adalah: Formica sanguine, Formica lemani, Pogonomyrmex badius, Trypodendron signatum, Xantholynus sp. Sedangkan INP spesies terendah adalah: Rhyzipagos cribratus, Platycerus carambides, Deporaus blatule, Bolithopagus reticulates, Evodinerus sp.

Parameter lingkungan yang terukur antara lain: $\mathrm{pH}$ tanah tertinggi 6,85 dan terendah 6,72, kelembabab tanah tertinggi $11,64 \%$ dan terendah $10,26 \%$, suhu tanah di tertinggi $24,88^{\circ} \mathrm{C}$ dan terendah $24,30{ }^{\circ} \mathrm{C}$.

\section{Hubungan Antara Faktor Fisik Kimia Lingkungan (pH, Kelembaban, suhu,) di Kawasan Hutan Gunung Sibela}

Berdasarkan hasil analisis Regresi tentang hubungan faktor fisik kimia lingkungan yang terdiri dari $\mathrm{pH}$, kelembaban, suhu, dengan biodiversitas (indeks keanekaragaman) epifauna tanah di hutan konservasi adalah terdapat hubungan antara faktor fisik kimia lingkungan ( $\mathrm{pH}$, kelembaban, suhu) dengan biodiversitas epifauna tanah di hutan konservasi pada kawasan hutan gunung Sibela. Dapat diketahui bahwa indeks keanekaragaman epifauna tanah di hutan konservasi dipengaruhi oleh $\mathrm{pH}$ dan suhu dengan persamaan regresi seperti di bawah ini: 
$Y=5,436-1,598 X 1+0,305 X 2+0,153 X 3$

Keterangan

$\mathrm{X} 1=\mathrm{pH}$

$\mathrm{X} 2=$ suhu

X3= Kelembaban

Berdasarkan persamaan Regresi di atas maka dapat diuraikan beberapa hal sebagai berikut:

- Konstanta sebesar 5,436 menyatakan bahwa jika variabel bebas dianggap konstan, maka rata-rata indeks keanekaragaman sebesar 5,436

- Koefisien regresi pH (X1) sebesar 1,598 menyatakan bahwa setiap perubahan $\mathrm{pH}$ akan meningkatkan indeks keanekaragaman sebesar 159,8 spesies epifauna tanah di hutan konservasi

- Koefisien regresi suhu (X3) sebesar 0,305 menyatakan bahwa setiap perubahan suhu akan meningkatkan indeks keanekaragaman sebesar 30,5 spesies epifauna tanah di hutan konservasi. Sumbangan relatif dan efektif kelembaban (X2) sebesar 1,53\% dan 1,38\%.

\section{PEMBAHASAN}

\section{Biodiversitas Epifauna Tanah di Hutan Konservasi Pada Kawasan Hutan Gunung Sibela}

Hasil penelitian ini menunjukkan bahwa epifauna tanah yang paling mendominasi adalah kelas insekta karena memiliki jumlah ordo, family, genus dan spesies terbanyak dibanding ketiga kelas lainnya. Hal ini sejalan dengan pernyataan Borror, dkk (1992) yang menyatakan bahwa insekta merupakan golongan hewan yang paling dominan di muka bumi ini dan populasinya melebihi populasi hewan yang lain. Suin (1997) menambahkan bahwa dari beberapa laporan penelitian tentang epifauna tanah diketahui bahwa ordo-ordo seperti Collembola, Hymenoptera, Coleoptera, Arachnida memiliki kepadatan populasi yang sangat tinggi. Yulipriyanto (2010) menyatakan bahwa fauna tanah pada umumnya baik yang hidup di dalam tanah maupun di permukaan tanah ada yang tinggal sementara dan ada yang bersifat menetap.

Indeks keanekaragaman epifauna tanah dalam penelitian ini menunjukkan bahwa epifauna tanah di kawasan hutan gunung Sibela pada hutan konservasi memiliki keanekaragaman SEDANG dan kesetabilan ekosistem SEDANG, sebagaimana yang dijelaskan oleh Wilhm dalam Leiwakabessi (1998) bahwa 1) jika H' < 1 maka keanekaragaman spesies rendah, penyebaran jumlah individu tiap spesies rendah dan kesetabilan ekosistem rendah; 2) jika $1<\mathrm{H}^{\prime}<3$ maka keanekaragaman spesies sedang dan kesetabilan ekosistem sedang; 3) jika H' > 3 maka keanekaragaman spesies tinggi, penyebaran jumlah individu tiap spesies tinggi dan kestabilan ekosistem tinggi.

Indeks kemerataan (evenes) spesies epifauna tanah pada kawasan hutan gunung Sibela menunjukkan bahwa indeks kemerataan epifauna tanah pada hutan konservasi sebesar 0,35089. Odum dalam Ramdiah (2005) menyatakan bahwa apabila nilai kemerataan suatu komunitas berada pada rentangan 0,6 - 0,8, maka komunitas tersebut dikatakan memiliki kemerataan yang seimbang atau 
dengan kata lain jumlah individu setiap jenis di dalam komunitas tersebut menyebar secara merata. Krebs dalam Leuwekabessy (1998) menyatakan bahwa jika spesies-spesies yang ditemukan pada suatu komunitas memiliki jumlah individu setiap spesies yang sama atau hampir sama maka kemerataan dalam komunitas tersebut tinggi.

Indeks dominansi epifauna tanah pada hutan konservasi sebesar 0,06280 yang menunjukkan indeks dominansi epifauna tanah cenderung rendah. Odum (1998) menyatakan bahwa keanekaragaman rendah jika hanya sedikit fauna yang dominan atau indeks dominansi tinggi. Berdasarkan hasil penelitian ini diketahui bahwa dengan indeks dominansi yang cenderung rendah maka terdapat kecenderungan keanekaragaman dan kemerataan spesies epifauna tanah di kawasan hutan gunung Sibela kategori sedang cenderung tinggi.

Indeks Nilai Penting (INP) spesies epifauna tanah tertinggi pada spesies Formica sanguine sebesar 20.9735, Formica Lemani sebesar 15.2824, Pogonomyrmex badius sebesar 14.7049, Trypodendron signatum sebesar 9.7723 dan Xantholinus sp sebesar 8.3308 . Nilai penting merupakan besaran yang menunjukkan kedudukan (dominansi) suatu jenis terhadap jenis lain dalam suatu komunitas. Makin besar nilai penting suatu jenis, maka perananya dalam komunitas semakin penting. Epifauna tanah mempunyai peranan penting dalam proses perombakan materi organik baik yang berasal dari hewan maupun tumbuhan yang telah mati. Bahan organik merupakan bahan yang penting dalam menentukan kesuburan tanah secara fisik kimia. Bahan organik merupakan sumber energi bagi kehidupan organisme tanah, apabial bahan organik dalam tanah tinggi maka aktivitas organisme akan meningkat dan aktivitas organisme akan turun seiring dengan menurunnya kandungan bahan organik. Aktivitas epifauna tanah, dan faktor lingkungan mempengaruhi produktivitas vegetasi dan sebaliknya vegetasi akan mempengaruhi aktivitas epifauna tanah melalui sumbangan bahan organik (Ramdiah, 2005).

\section{Hubungan Antara Faktor fisik kimia Lingkungan (suhu, pH, Kelembaban) dengan Biodiversitas Epifauna di Kawasan Hutan Gunung Sibela}

Hubungan faktor fisik kimia dengan indeks keanekaragaman jenis epifauna tanah di hutan konservasi, hal ini dapat dilihat pada kelimpahan ordoordo epifauna tanah yang dapat menanggapi faktor fisik kimia. Ordo-ordo tersebut antara lain: Hymenpotera, dan Coleoptera. Derajat keasaman $(\mathrm{pH})$ dan suhu merupakan faktor pembatas bagi kehidupan organisme baik flora maupun fauna tanah. $\mathrm{pH}$ tanah dapat menjadikan organisme mengalami kehidupan yang tidak sempurna atau mati pada $\mathrm{pH}$ yang terlalu asam atau terlalu basa (Heddy, dalam Ramdiah,2005). Dengan kata lain $\mathrm{pH}$ tanah berpengaruh terhadap keadaan fisik kimia tanah yang penting bagi kelangsungan hidup organism tanah (Yulipriyanto, 2010).

\section{Implikasi Hasil Penelitian Pada Bidang Pendidikan}

Pendekatan kontekstual menyatakan bahwa proses pembelajaran bagi peserta didik dengan menggunakan lingkungan sebagai sumber dan media pembelajaran akan memberikan kebermaknaan proses dan hasil belajar. 
Pembelajaran kontekstual memungkinkan peserta didik memperoleh informasi, pengetahuan, pengalaman dan keterampilan belajar secara nyata.

Kajian Biodiversitas epifauna tanah pada kawasan hutan gunung Sibela dalam penelitian ini merupakan salah satu bentuk kegiatan praktikum yang dapat membantu pemahaman mahasiswa tentang konsep-konsep dalam ilmu Ekologi dan Entomologi khususnya tentang konsep keanekaragaman epifauna tanah (serangga tanah). Mengamati dan mempelajari fenomena alam melalui kegiatan praktikum di alam dapat memberikan manfaat antara lain: 1) peserta didik akan mempunyai kemampuan menganalisis dan mengorganisasikan fenomena yang terjadi pada obyek pengamatan, 2) peserta didik akan mempuyai serangkaian informasi dan masalah kontekstual dan hal-hal baru yang selanjutnya dapat dikembangkan menjadi masalah penelitian ilmiah (Subiyanto, 1990; Mahani, 1998). Melalui penelitian ini dapat diketahui bahwa Maluku Utara khususnya di Kabupaten Halmahera Selatan (pada lokasi penelitian), mempuyai potensi Sumberdaya Alam hutan yang luas yang memiliki keanekaragaman hayati yang tinggi, termasuk epifauna tanah yang dapat digunakan sebagai media dan sumber belajar bagi matakuliah Ekologi berbasis pendidikan lingkungan. Melalui kegiatan praktikum dan penelitian di lingkungan sekitar akan memberikan wawasan baru menganalisis masalah dimasyarakat serta menanamkan nilai nilai secara langsung kepada mahasiswa untuk dapat mengambil keputusan dalam upaya penyelamatan Lingkungan (hutan), dalam penelitian ini dikaji secara khusus pada aspek studi tingkat persepsi masyarakat sekitar hutan gunung Sibela tentang fungsi ekologis hutan

Hasil penelitian ini memberikan informasi tentang keanekaragaman epifauna tanah (arthropoda) dalam bentuk foto-foto hasil penelitian, teknik identifikasi dan referensi bagi kegiatan penelitian tentang identifikasi arthropoda tanah. Secara umum foto-foto tersebut dapat digunakan sebagai media pembelajaran. Penggunaan media pembelajaran diharapkan dapat membantu peserta didik dalam proses transfer dan pemahaman materi yang diajarkan. Degeng (2000) menyatakan bahwa media pembelajaran adalah komponen strategi penyampaian materi yang disampaikan kepada peserta didik yang dapat berupa alat, orang atau barang yang mencakup semua sumber yang diperlukan untuk komunikasi antara pendidik dan peserta didik.

Hasil penelitian ini juga memberikan sumbangan praktis tentang prosedur penelitian desain sederhana teknik pembuatan perangkap epifauna tanah (trap) dalam bentuk Pitfall trap. Selama ini kajian tentang serangga tanah dan prosedur penangkapan serangga tanah (arthropoda tanah) masih sangat kurang dilakukan oleh dosen dan mahasiswa bidang minat Ekologi maupun Entomologi di Universitas Khairun Ternate.

\section{KESIMPULAN}

Berdasarkan hasil penelitian ini, dapat disimpulkan sebagai berikut:

1. Biodiversitas epifauna tanah pada hutan konservasi adalah sebagai berikut: (1) indek keanekaragaman sebesar 1,46475 kategori sedang, (2) indeks kemerataan sebesar 0,35089 kategori kemerataan seimbang, (3) indeks dominansi sebesar 0,06280 kategori dominansi yang cenderung rendah, (4) Nilai penting epifauna tertinggi pada spesies Formica sanguine sebesar 20.9735. Epifauna tanah pada kawasan hutan gunung Sibela yang ditemukan 
dalam penelitian ini sebanyak sebanyak 74 spesies epifauna yang terdiri dari 4 kelas, 18 ordo, 36 famili dan 63 genus.

2. Adanya hubungan yang signifikan antara faktor fisik-kimia lingkungan $(\mathrm{pH}$, kelembaban, dan suhu) dengan indeks keanekaragaman epifauna tanah di hutan konservasi. $\mathrm{pH}$ dan suhu memberikan sumbangan efektif tertinggi terhadap indek keanekaragaman epifauna tanah di hutan konservasi.

\section{DAFTAR RUJUKAN}

Andianto 1993. Fauna tanah \& peranannya dalam ekosistem. jakarta: Depdikbud Borror, T. \& Jonson. 1992. Pengenalan Pelajaran Serangga. Yogyakarta: Gadjah Mada University Press.

Handayanto E \& Hairiah K, 2007. Biologi Tanah Landasan Pengelolaan Tanah Sehat. Yagyakarta: Pustaka Adipura.

Leiwakabessy, F. 1998. Gastropoda di Perairan Pasang surut Ambon. Analisis Keanekaragamandan Penyusunan Penuntun Identifikasi Dikotomis Atas dasar Cangkang. Tesis tidak diterbitkan. Malang: Program Pasca Sarjana Universitas Negeri Malang

Mahani 1990. Diatom sebagai Bioindikator Kualitas Air Sungai (Studi di Sungai Kali Brantas). Malang: PPS UM.

Odum 1993. Dasar-Dasar Ekologi Edisi Ketiga. Alih Bahasa Oleh Cahyono Sumingan. Yogyakarta: UGM Press.

Ramdiah, S. 2005. Kajian Struktur Komunitas Epifauna Tanah di Lahan Gambut Kec. Sei Tabuk Kab. Banjar. Tesis tidak diterbitkan. Malang: Program Pasca Sarjana Universitas Negeri Malang

Subiyanto, 1990. Pendekatan dan Metode pembelajaran Sains. Malang: IKIP Malang

Soemarwoto O, 1997. Ekologi Lingkungan Hidup dan Pembangunan. Bandung: Penerbit Djambatan

Suin, N. M. 1997. Ekologi Fauna tanah. Jakarta; Bumi Aksara dan Pusat Antar Universitas Ilmu Hayati dan Institut Teknologi Bandung

Southwood, 1966. Procedura and Method Of. Pithfall Traps. New York: Mcmillan Company..

Yulipriyanto H, 2010 Biologi Tanah dan Strategi Pengolahannya. Edisi Pertama. Yogyakarta: Graha Ilmu. 